\title{
Trabalhonecessário
}

Issn: $1808-799 X$

ano 14, número $24-2016$

\section{OS (RE) SIGNIFICADOS DA INFORMALIDADE NO MUNDO DO TRABALHO CONTEMPORÂNEO}

\author{
Andreza Gomes Weil ${ }^{1}$ \\ Marinez Gil Nogueira²
}

\section{Resumo}

A compreensão sobre a dinâmica do mundo do trabalho contemporâneo perpassa um olhar sobre as diversas formas de exploração que se apresentam no atual contexto. Os novos modelos de gestão, impulsionados pela reestruturação produtiva, reconfiguram as relações de trabalho e tem como resultado um alto índice de desemprego. Neste cenário, a Informalidade se apresenta como alternativa para muitos trabalhadores. O que se verifica é que este fenômeno vem ganhando espaço no mundo do trabalho com outras roupagens que em geral tem ocultado o caráter da precarização. Este artigo busca analisar abordagens teóricas acerca da Informalidade e suas particularidades no cenário contemporâneo.

Palavras-Chave: Trabalho, Informalidade, Precarização

\section{ABSTRACT}

The understanding of the dynamics of the contemporary workplace permeates a look at the various forms of exploitation that arise in the current context. The new

1 Doutoranda em Ciências do Ambiente e Sustentabilidade na Amazônia. Mestra em Serviço Social e Sustentabilidade na Amazônia. Professora do Colegiado de Serviço Social do Instituto de Ciências Sociais, Educação e Zootecnia da Universidade Federal do Amazonas. andrezaweil@gmail.com

2 Doutora em Biotecnologia na área de Gestão da Inovação pelo Programa Multi-Institucional de Pós-graduação em Biotecnologia - UFAM/INPA. Mestra em Ciências Sociais na área de Desenvolvimento Regional pela Universidade Federal do Rio Grande do Norte. Professora do Departamento de Serviço Social da Universidade Federal do Amazonas. mgnogueira@yahoo.com.br 


\section{Trabalhonecessário}

Issn: $1808-799 X$

ano 14, número $24-2016$

management models, driven by productive restructuring, reconfigure labor relations and results in a high rate of unemployment. In this scenario, the informality is an alternative for many workers. What is happening is that this phenomenon is becoming more popular in the working world with other garments which in general has concealed the nature of precariousness. This article seeks to analyze theoretical approaches to the informality and its particularities in the contemporary scene.

Keywords: Work, Informality, Insecurity

\section{Introdução}

A dinâmica do Mundo do Trabalho contemporâneo é permeada por transformações que moldam novas formas de exploração dos trabalhadores. Tais situações se revelam de forma visível nas relações de trabalho estabelecidas no atual contexto e estas se expressam, por exemplo, no crescimento da terceirização, dos contratos por tempo determinado, das exigências impostas aos trabalhadores e outras situações de uma conjuntura cada vez mais manipuladora.

As formas de controle sobre o trabalho, bem como o desenvolvimento tecnológico, tendem a contribuir para a expansão do capital e a manutenção da ordem produtiva. Porém, o efeito contrário desse processo se traduz na desordem do trabalho, expressa na intensificação do processo de alienação e na desarticulação política da classe trabalhadora.

Tal situação ainda tem como consequência a redução do mercado de trabalho formal e a desregulamentação das relações trabalhistas, situações que geram o desemprego e o aumento das desigualdades. Longe de encontrar saídas, os trabalhadores buscam alternativas de sobrevivência em outras formas de trabalho que estão situadas principalmente na Informalidade.

A informalidade não é um fenômeno novo, historicamente muitas atividades assumem a característica de informais. Entretanto, a diferença no 


\section{Trabalhonecessário}

Issn: $1808-799 X$

ano 14, número $24-2016$

atual contexto são os novos significados assumidos por este fenômeno, que ocultam o caráter do trabalho precário que é próprio destas atividades.

Este artigo busca analisar estas particularidades a partir de abordagens teóricas que discutem a Informalidade sob diferentes olhares. Entende-se que esta é uma temática relevante para as discussões acerca do Mundo do Trabalho Contemporâneo, especialmente quando se considera o expressivo número de trabalhadores que atuam no mercado informal.

\section{A Desordem do Trabalho na cena contemporânea}

As reflexões acerca da categoria Trabalho assinalam diversas concepções quanto a sua dinâmica, porém, é consenso o fato de que esta atividade é intrínseca à vida social. Dentre as diferentes concepções sobre o trabalho é possível afirmar que o entendimento desta categoria torna-se bem mais esclarecedor a partir dos escritos de Karl Marx, que analisa o trabalho a partir das relações que o homem estabelece com a natureza, particularizando sua dinâmica no contexto do processo de produção do capitalismo.

Conforme Marx (1998), o trabalho é um processo em que participam o homem e a natureza, um processo em que o ser humano com sua própria ação, impulsiona, regula e controla sua ação sobre a natureza. Neste sentido, esta relação concretiza a vida humana e esse processo só ocorre por meio do trabalho, onde o homem modifica a natureza externa e ao mesmo tempo modifica sua própria natureza, visto que desenvolve potencialidades e submete ao seu domínio as forças naturais (MARX, 1998).

Para tanto, o autor destaca que este processo exige a articulação entre os seguintes elementos: a atividade adequada a um fim (o trabalho), a matéria que se aplica ao trabalho (o objeto) e os meios de trabalho (os instrumentais). 


\section{Trabalhonecessário}

Issn: $1808-799 X$

ano 14, número $24-2016$

A dinâmica de processo de trabalho ocorre em qualquer estrutura social e faz parte da sobrevivência do homem, consolidando sua relação com a natureza. Entretanto, no contexto do modo de produção capitalista os elementos necessários à sua concretização são modificados, tendo por fundamento a subordinação do trabalho ao capital.

De acordo com Marx (1998) neste sistema, a força de trabalho é oferecida como mercadoria pelo seu possuidor (trabalhador) ao proprietário do dinheiro (capitalista) que ao comprá-la incorpora o trabalho aos meios de produção, sendo assim, o processo de trabalho ocorre entre coisas que o capitalista comprou e entre coisas que lhe pertencem (MARX, 1998).

As análises de Mészaros (2002) acerca desse processo sinalizam a existência de um sistema de mediação de primeira e segunda ordem ${ }^{3}$, onde, a segunda se interpõe como mediação destrutiva da primeira, caracterizada pela relação entre os seres humanos e a natureza.

Mészaros (2002) ainda sugere que essa lógica destrutiva se acentuou no capitalismo contemporâneo originando a taxa de utilização decrescente do valor de uso das coisas ${ }^{4}$, em outras palavras, o tempo de vida útil das mercadorias são reduzidos de modo a agilizar o ciclo produtivo. Para este autor, este fenômeno vem se acentuando desde os anos de 1970, quando o sistema global do capital

\footnotetext{
${ }^{3}$ Mészáros apud Antunes (2009, p.21-22) aponta que as mediações de primeira ordem têm as seguintes características: 1) Os seres humanos são parte da natureza, devendo realizar suas necessidades elementares por meio do constante intercambio com a própria natureza; 2) Eles são constituídos de tal modo que não podem sobreviver como indivíduos da espécie a qual pertencem (...) baseados em um intercambio sem mediações com a natureza, regulados por um comportamento instintivo determinado diretamente pela natureza, por mais complexo que esse comportamento instintivo possa ser.

Já as mediações de segunda ordem, alteram estas relações e surgem no contexto do capitalismo e constituem-se um círculo vicioso do qual não há fuga, onde as condições de reprodução social estão totalmente subordinadas ao aspecto produtivo do capital (Meszaros, 2002, p.179-180).

${ }^{4}$ Mészáros (2002) afirma que o capital não considera valor de uso e valor de troca como coisas separadas, mas como um modo que subordina radicalmente o primeiro ao último (...) o que significa que uma mercadoria pode passar de um extremo ao outro sem jamais ser usada, mas nem por isso deixa de ter para o capital sua utilidade expansionista (p.27-28).
} 


\section{Trabalhonecessário}

Issn: $1808-799 X$

ano 14, número $24-2016$

vivencia uma grave crise estrutural evidenciada no modelo de produção Taylorista-fordista.

Conforme Antunes (2009), os principais indícios desta crise foram: a queda da taxa de lucro, esgotamento do padrão de acumulação Taylorista/Fordista, hipertrofia da esfera financeira, maior concentração de capitais em razão da fusão entre as empresas, crise do Estado de Bem-Estar Social e o crescimento das privatizações.

Para Pinto (2010), a instabilidade macroeconômica do modelo TayloristaFordista obrigou a indústria a redirecionar suas estratégias de padronização em larga escala para a inserção de novas tecnologias e organização do trabalho, o que colocou este sistema em questionamento, pois sua unidade produtiva altamente concentrada tornou-se uma camisa de força para o crescimento.

Tal cenário exigiu então a execução de estratégias para o enfrentamento da crise e reordenamento do capital, o que culminou no processo de reestruturação das bases sociais, econômicas e políticas do capitalismo. Conforme Antunes (2009, p.49):

O capital deflagrou, então, várias transformações no próprio processo produtivo, por meio da constituição das formas de acumulação flexível, do downsizing, das formas de gestão organizacional, do avanço tecnológico, dos modelos alternativos ao binômio taylorismo/fordismo em que se destaca o toyotismo ou modelo japonês.

No modelo de produção Toyota identificam-se todas as transformações ocorridas no contexto da reestruturação do capital, sejam estas na esfera produtiva ou no que se refere à organização do trabalho. Pinto (2010) afirma que o modelo Toyota superou em produtividade todos os outros sistemas de organização flexível, quando evita o confronto entre classe trabalhadora e empresariado e se aproveita da manipulação da subjetividade dos trabalhadores, buscando a exploração de seus conhecimentos. 


\section{Trabalhonecessário}

Issn: $1808-799 X$

ano 14, número $24-2016$

As formas de controle sobre o trabalho, bem como o desenvolvimento tecnológico, tendem a contribuir para a expansão do capital e a manutenção da ordem produtiva. Porém, o efeito contrário desse processo é desastroso e traduz-se na desordem do trabalho e na intensificação do processo de alienação, bem como na desarticulação política da classe trabalhadora.

A partir desta dinâmica, verificam-se novas formas de intensificação do trabalho fundamentadas na redução do numero de trabalhadores, porém, com vistas aos aumento da produtividade. Este fenômeno ocorre prioritariamente por dois motivos: a inserção de novas técnicas de gestão da força de trabalho e a introdução ampliada das tecnologias.

Destaca-se como pano de fundo deste contexto, a transnacionalização do capital, caracterizada pela flexibilização e a abertura de fronteiras dos mercados nacionais permitindo a industrialização em escala mundial. Tal cenário teve como consequência o aumento da competitividade entre as empresas e o processo desigual de produção e comercialização, uma vez que existia uma forte diferença na dinâmica das economias periférica e central.

Conforme Silva (2010, p.26) estas mudanças ganharam reforço com o advento do modelo neoliberal e marcam de uma série de transformações de ordem econômica e social, gerando a desregulamentação do mercado financeiro e o desmonte das relações de trabalho, fatores que culminam com o aumento do desemprego e da exclusão social.

Estas modificações aconteceram em nível global e não se concentram apenas nos países centrais, aos poucos se expandem também para os países periféricos provocando, nas palavras de Silva (2010), uma globalidade desigualmente combinada. 


\section{Trabalhonecessário}

Issn: $1808-799 X$

ano 14, número $24-2016$

No Brasil, estas modificações ganham espaço na década de 1990, com a implantação da política econômica neoliberal estabelecida no Governo Collor ${ }^{5}$.

Este período é marcado pela profunda desestabilização do mercado de trabalho e consequentemente pelo alto índice de desemprego e a precarização das condições e relações entre capital e trabalho. Conforme Mattoso (1999), o agravamento desta problemática ocorreu no primeiro governo de Fernando Henrique Cardoso, que apresentou uma acentuada redução da capacidade de geração de empregos formais.

A diretriz da política econômica instalada neste período provocou um processo de reestruturação da economia voltado para a abertura externa da base produtiva local, apontada como a única forma de modernização econômica para o país. Além disso, a política conservadora compreendia que o Estado era paternalista e, por isso, suas funções deveriam ser privatizadas (DEDECCA, 2005).

Notadamente, as políticas implementadas no país na década de 1990, antes de tudo buscavam enfraquecer e desmobilizar os instrumentos de regulação do mercado e das relações de trabalho estabelecidos na Constituição Federal de 1988. Contraditoriamente, afirmava-se que o problema do emprego estava relacionado à regulação excessiva das relações de trabalho impostas pela proteção social.

De acordo com Matoso (2000) "ao longo dos anos 90 foram queimados cerca de 3,3 milhões de postos de trabalho formais da economia brasileira, sendo que desde que FHC assumiu em 1995 foi contabilizada uma queima de 1,8milhão de empregos formais". Sobre este período Malaguti (2000) assinala que o desemprego, os baixos salários e a concentração de rendas deixaram de serem

\footnotetext{
${ }^{5}$ De acordo com Silva apud Silva (2010, p. 60) "a reestruturação produtiva no Brasil é marcada por três momentos distintos: a primeira fase compreende o final dos anos 70 e o inicio dos anos 80; a segunda fase abrange o período de 1984 a 1989; e a terceira tem inicio em 1990 e se estende até os dias atuais."
}

TrabalhoNecessário - www.uff.br/trabalhonecessario; Ano 14, № 24/2016. 


\section{Trabalhonecessário}

Issn: $1808-799 X$

ano 14, número $24-2016$

fenômenos apenas para operários ou trabalhadores menos qualificados, em poucos anos a classe média também seria inseridas neste contexto.

Além dos efeitos negativos da redução do gasto social imposto pela política neoliberal, o processo de racionalização produtiva da indústria agravou ainda mais as problemáticas sociais e econômicas evidenciadas neste período. A existência de um grande fluxo de recursos externos gera um processo de internacionalização da propriedade industrial e o estabelecimento de uma dependência produtiva de insumos importados. O resultado desta conjuntura foi o déficit em conta corrente e a retração do emprego no grande setor da economia, o que gerou um elevado índice de desemprego no país (DEDECCA, 2005).

Para Singer (2006) o termo precarização do trabalho expressa melhor este período pois além de reduzir a ocupação ${ }^{6}$, provoca o desemprego estrutural, ou seja, os trabalhadores vítimas da desindustrialização encontram muitas dificuldades para se reintegrarem no mercado de trabalho.

Nestes termos, Antunes (2005) sinaliza que o mundo contemporâneo fez explodir o universo do não trabalho, o desemprego, visto que quase um terço da força trabalho passa a exercer trabalhos parciais, precários, informais, temporários ou mesmo vivencia o não trabalho.

Esta realidade preocupante atinge principalmente a classe trabalhadora que vivencia, entre outros agravantes, a desregulamentação das relações trabalhistas e o alto índice de desemprego. Diante deste processo, para garantir sua sobrevivência, os trabalhadores buscam alternativas de trabalho que, em geral, estão relacionadas à Informalidade.

\footnotetext{
${ }^{6}$ Singer (2006) estabelece uma clara diferença entre emprego e ocupação. Para este autor o emprego resulta de um contrato pelo qual o empregador compra a força de trabalho ou a capacidade de produzir do empregado. A ocupação por sua vez compreende toda a atividade que proporciona sustento a quem exerce. Desta forma o autor afirma que a sociedade necessita de ocupação e não de emprego.
} 


\section{Trabalhonecessário}

Issn: $1808-799 X$

ano 14, número $24-2016$

Informalidade como expressão da precarização do Trabalho: apontamentos e reflexões

As acepções acerca da Informalidade levantam inúmeros questionamentos, visto que essa categoria é compreendida a partir de diferentes marcos teóricos.

As atividades informais são seculares, porém, o caráter precário expresso nesta forma de trabalho é indiscutível e as transformações ocorridas no contexto da divisão do trabalho nas últimas décadas contribuem para o entendimento de que, no atual contexto, a informalidade configura-se como uma expressão da questão social. Para tanto, a compreensão desta dinâmica requer o conhecimento das diferentes concepções acerca da informalidade, seja na perspectiva conceitual ou histórica.

Para Singer (2000) o trabalho informal data dos primórdios da Revolução Industrial e já era sinalizado por Marx no contexto da categoria de população relativamente excedente ${ }^{7}$. De acordo com 0 autor, o trabalho informal corresponde ao segmento estagnado da população excedente, ou seja, aquele trabalhador que faz parte do exército ativo do trabalho, mas com ocupação inteiramente irregular, em outras palavras:

Trata-se do exército industrial ativo e não de reserva, este formado pelos sem trabalho, pelos desempregados no sentido estrito do termo. Os desempregados vivem do segurodesemprego (enquanto dura) ou são sustentados por economias ou pelo que ganham outros membros da família (...) os trabalhadores informais já desistiram de procurar emprego, eles saem à luta tentando ganhar a vida de qualquer jeito (SINGER, 2000, p. 12)

\footnotetext{
${ }^{7}$ Com base em Marx, Singer (2000) aponta que a população relativamente excedente pode ser dividida em liquida, latente e estagnada. A primeira refere-se a uma reserva móvel de trabalho, sempre disponível às empresas quando estas querem expandir rapidamente o mercado de trabalho. A segunda é formada pelos trabalhadores do campo que estão em via de ser expulsos da agricultura e preparam-se para integrar a população urbana em busca de trabalho. E a terceira forma parte do exercito ativo de trabalho, mas com ocupação inteiramente irregular, oferecendo ao capital uma inesgotável força de trabalho disponível.
}

TrabalhoNecessário - www.uff.br/trabalhonecessario; Ano 14, № 24/2016. 


\section{Trabalhonecessário}

Issn: $1808-799 X$

ano 14, número $24-2016$

A primeira iniciativa de investigação sobre a informalidade ocorreu em 1969, com o lançamento do Programa Mundial de Emprego instituído pela Organização Internacional do Trabalho. O programa tinha como objetivo avaliar os efeitos das estratégias de aceleração econômica dos países periféricos sobre o emprego e a distribuição de renda. O diagnóstico apontou que o crescimento econômico era insuficiente na geração de empregos e, como consequência, fundava-se um expressivo excedente de mão de obra que não aparecia como forma de desemprego, mas em atividades realizadas em pequena escala.

Conforme Theodoro (2000, p.28), neste período surge o conceito de setor informal, "como um instrumento explicativo para um velho fenômeno: a existência de atividades econômicas de baixa produtividade que se desenvolviam a margem da legislação nas franjas do mercado."

O trabalho realizado pela Organização Internacional do Trabalho (OIT) culminou na definição de setor informal e pontuaram um conjunto de características que compõem esta dinâmica, sendo as seguintes: Propriedade familiar do empreendimento, origem e aporte próprio dos recursos, pequena escala de produção, facilidade de ingresso, uso intensivo do fator trabalho e de tecnologia adaptada, aquisição das qualificações profissionais à parte do sistema escolar de ensino e Participação em mercados competitivos e não regulamentados pelo Estado.

Ainda no final da década de 1960, a OIT cria o Programa Regional de Emprego para a América Latina e Caribe (PREALC) que realizou estudos sobre o desenvolvimento econômico dessas regiões. Para o PREALC as diferenças existentes na estrutura produtiva originavam dois setores no mercado de trabalho urbano: o setor formal composto pelas ocupações em empresas organizadas e o setor informal estruturado pelas atividades de baixo nível de produtividade que são exercidas por trabalhadores independentes e por empresas pequenas.

Tais concepções do PREALC são questionáveis, uma vez que o cenário econômico, político e social à época denota novas configurações para a 


\section{Trabalhonecessário}

Issn: $1808-799 X$

ano 14, número $24-2016$

Informalidade que começam a ser discutidas em âmbito acadêmico. Em 1991 a questão da Informalidade torna-se o centro dos debates da OIT sendo apontada como um "setor não estruturado." O principal direcionamento era aproveitar o potencial das atividades informais, para a geração de ocupação e renda para uma parcela da população menos favorecida (KREIN e PRONI, 2010). Porém, as diferenças econômicas e culturais entre os países, bem como a classificação universal das atividades do chamado setor informal impediram o desenvolvimento da discussão.

No decorrer dos anos 1990, o aumento da informalidade gerou impactos na dinâmica econômica dos países em desenvolvimento, levantando discussões em torno de políticas públicas de trabalho e renda, bem como na reforma do sistema de relações de trabalho.

De acordo com Krein e Proni (2010), tal cenário culminou na mudança conceitual $^{8}$ do termo setor informal para economia informal, pois de acordo com a OIT, "ao ocupar um grande contingente de pessoas sem possibilidade de garantir um "bom emprego", o setor informal estava desempenhando um papel relevante na geração de renda para uma parcela expressiva da população" (idem, p.12).

Os autores ainda afirmam que, com base neste conceito, foram adotados critérios de unidade produtiva e ocupação sendo definidas as seguintes categorias:

- Trabalhadores independentes típicos (microempresa familiar, trabalhador em cooperativa, trabalhador autônomo em domicilio);

- "Falsos" autônomos (trabalhador terceirizado, subcontratado, trabalho em domicilio, trabalhador em falsa cooperativa, falsos voluntários do terceiro setor);

\footnotetext{
${ }^{8}$ Este conceito foi definido em 2002 na $90^{\circ}$ Conferência Internacional do Trabalho.
} 


\section{Trabalhonecessário}

Issn: $1808-799 X$

ano 14, número $24-2016$

- Trabalhadores dependentes flexíveis e/ou atípicos (assalariados de microempresas, trabalhador em tempo parcial, emprego temporário ou por tempo determinado, trabalhador domestico, "teletrabalhadores");

- Microempregadores;

- Produtores para autoconsumo;

- Trabalhadores voluntários do terceiro setor e da economia solidária.

Verifica-se que as mudanças estruturais ocorridas no contexto produtivo, alteram a primeira concepção da OIT sobre o então setor informal. Entretanto, estas modificações favorecem prioritariamente o capital, pois no contexto da informalidade as ocupações são geradas a baixo custo e as relações de trabalho são fragmentadas.

Sob esta ótica, Lautier apud Tavares (2004) afirma que a existência de empregos e de trabalhos sob relações informais não estão à margem do capital, mas integrados por um caráter que a própria estrutura capitalista Ihe imprime.

Tal evidência é confirmada por Malaguti (2000) que sinaliza os numerosos casos de informalidade que podem ser evidenciados no setor formal e traz como exemplo a situação de funcionários públicos ou assalariados de empresas multinacionais que durante 0 expediente vendem produtos diversos como garantia de renda extra. Neste caso, para Malaguti "(...)a formalidade penetra o setor informal e o setor informal nutre-se da informalidade. Desta forma, a existência de uma sem a outra, parece uma prática inconcebivel." (2000,p.101).

Tavares (2004) considera a relação formalidade/informalidade sobre outro olhar. Para esta autora, considerando o cenário atual, verifica-se que a informalidade está no setor formal, "suscitada pela política de flexibilização da economia que se expande mediante processos de terceirização, cujos mecanismos obscurecem a extração de sobre trabalho" (idem, p.45). Assim, pode-se afirmar que o trabalho informal constitui-se como: 


\section{Trabalhonecessário}

Issn: $1808-799 X$

ano 14, número $24-2016$

O emprego desprotegido, sem vínculo formal, mas diretamente vinculado à produção capitalista. Trata-se de formas de trabalho que foram praticadas pela sociedade pré-industrial e são agora retomadas pela grande empresa, que tende a deixar de ser 0 lugar por excelência da chamada relação salarial moderna (...) Nenhuma forma de trabalho pode ser mais flexível que o trabalho informal (TAVARES, 2004, p.52)

Para Cacciamali (2000) o entendimento sobre a informalidade na atualidade perpassa às mudanças estruturais e seus efeitos, ocorridos no processo de reestruturação do capital. O cenário em questão cria um ambiente de incerteza nos negócios com menores taxas de crescimento econômico e, consequentemente, fortes impactos sobre o mercado de trabalho, gerando o desemprego.

Essas mudanças estruturais incidem no que Cacciamali (2002) define como Processo de Informalidade, ou seja, a redefinição das relações de produção e da forma de inserção dos trabalhadores no contexto produtivo. Para esta autora, dois fenômenos marcam este processo: a reorganização do trabalho assalariado e o auto-emprego.

O primeiro refere-se à reformatação das relações de trabalho expressas por contratações precárias sob a forma de serviços temporários, locação de mãode-obra, cooperativas de trabalho e outros. De acordo com a autora, estes contratos penetram o espaço produtivo de bens e serviços e tem características comuns assim definidas:

Vulnerabilidade, ou seja, a insegurança da relação de trabalho e na percepção da renda; a ausência muitas vezes de qualquer regulamentação laboral e de proteção social, especialmente contra demissões e acidentes de trabalho; o uso flexível do trabalho (horas e múltiplas funções); e frequentemente menores salários, principalmente para os menos qualificados (CACCIAMALI, 2000, p.164) 


\section{Trabalhonecessário}

Issn: $1808-799 X$

ano 14, número $24-2016$

Quanto ao fenômeno do auto-emprego a autora sinaliza que este funciona como estratégia de sobrevivência para as pessoas que apresentam dificuldade em ingresso no mercado de trabalho, ou mesmo por opção, quando decidem investir sua renda em trabalho por conta própria ou microempresas. Este grupo trabalha diretamente na produção ou prestação de serviços, que ocupam interstícios no mercado de bens e que se modificam de acordo com a demanda capitalista.

Acerca desta concepção Tavares (2004) sinaliza que o trabalho autônomo, trabalho assalariado e trabalho familiar, configuram-se como um processo estratégico para disfarçar as desigualdades existentes na relação capital e trabalho pois:

Trata-se de uma situação em que o sujeito é proprietário dos meios de produção e de conhecimentos necessários à realização de uma determinada atividade, que ele pode realizar sozinho, ou com a ajuda da família, ou com a ajuda de outros trabalhadores. Mas o fato de ser proprietário dos meios de produção, o que lhe permite oferecer ocupações a outras pessoas, fazendo dele um empregador, não faz necessariamente daqueles meios capital, nem do sujeito um capitalista. Ele é apenas um pequeno patrão (idem, p.31-32)

Neste sentido, convém apresentar as concepções de Alves e Tavares (2009) que buscaram categorizar os trabalhadores a partir do que denominam novo modo de ser da informalidade. O termo refere-se a ampliação acentuada de trabalhos submetidos a contratos temporários, sem estabilidade ou sem carteira assinada, mesmo atuando dentro ou fora das empresas, seja em atividades mais instáveis ou temporárias ou mesmo na condição de desempregado. O Quadro 1 sintetiza estas questões.

\section{Novos Modos de Ser da Informalidade}

\begin{tabular}{|c|l|}
\hline \multicolumn{2}{|c|}{ Novos Modos de Ser da Informalidade } \\
\hline Categoria & Característica \\
\hline & - Inseridos em atividades que requerem baixa capitalização; \\
& - Buscam obter renda para consumo individual e familiar; \\
\hline
\end{tabular}

TrabalhoNecessário - www.uff.br/trabalhonecessario; Ano 14, № 24/2016. 


\section{Trabalhonecessário}

Issn: $1808-799 X$

ano 14, número $24-2016$

\begin{tabular}{|c|c|}
\hline \multirow{5}{*}{$\begin{array}{c}\text { Trabalhadores Informais } \\
\text { Tradicionais }\end{array}$} & $\begin{array}{l}\text { - Vivem de sua força de trabalho podendo solicitar auxilio de } \\
\text { familiares ou de ajudantes temporários } \\
\text { - São classificados em: menos instáveis, instáveis e } \\
\text { ocasionais ou temporários. } \\
\text { Menos Instáveis }\end{array}$ \\
\hline & $\begin{array}{l}\text {-Possuem um mínimo de conhecimento profissional e os } \\
\text { meios de trabalho; } \\
\text { - Desenvolvem atividades no setor de prestação de serviços } \\
\text { (terceirização). } \\
\text { Exemplo: jardineiros, costureiras, pedreiros, vendedores } \\
\text { ambulantes e outros. }\end{array}$ \\
\hline & Instáveis \\
\hline & $\begin{array}{l}\text {-São recrutados temporariamente sendo remunerados por } \\
\text { peça ou serviço executado; } \\
\text { - Ocupam trabalhos eventuais que dependem de sua força } \\
\text { física e da disposição para determinadas tarefas. } \\
\text { Exemplo: carregadores e carroceiros de rua em geral. } \\
\text { Ocasionais ou Temporários }\end{array}$ \\
\hline & $\begin{array}{l}\text { - Quando estão desempregados se encaixam nas atividades } \\
\text { informais mas seu objetivo é retornar ao trabalho } \\
\text { assalariado; } \\
\text { - São trabalhadores que ora estão desempregados, ora são } \\
\text { absorvidos pelo trabalho precário; } \\
\text { - Há casos que combinam o trabalho regular com o } \\
\text { ocasional, os chamados bicos } \\
\text { Exemplo: digitador, salgadeiras, faxineiras e outros. }\end{array}$ \\
\hline $\begin{array}{c}\text { Trabalhadores Assalariados } \\
\text { Sem Registro }\end{array}$ & $\begin{array}{l}\text { - Por não serem registrados não tem acesso as resoluções } \\
\text { dos acordos coletivos de sua categoria e nem recebem } \\
\text { seguro desemprego; } \\
\text { - Muitos atuam em domicilio outros prestam serviço as } \\
\text { grandes empresas que se utilizam da subcontratação para } \\
\text { montagem de bens, produção de serviços distribuição de } \\
\text { bens por meio do comercio de rua; } \\
\text { - Grande parte atua em empresas com até } 5 \text { empregados; } \\
\text { - Normalmente tem nível de instrução baixo e não } \\
\text { contribuem com a previdência social. }\end{array}$ \\
\hline $\begin{array}{l}\text { Trabalhadores por } \\
\text { Própria }\end{array}$ & $\begin{array}{l}\text { - Produtor simples de mercadoria que conta com a força de } \\
\text { trabalho própria ou de familiares e, em alguns casos, } \\
\text { subcontrata força de trabalho assalariada; } \\
\text { - A atividade possibilita apenas uma renda necessária à } \\
\text { sobrevivência dos trabalhadores; } \\
\text { - Estes trabalhadores possuem pequenos negócios que são } \\
\text { vinculados a grandes corporações envolvendo as áreas de } \\
\text { produção, comercio e prestação de serviço; } \\
\text { - Por meio da ajuda de membros da família reduz o custo de } \\
\text { reprodução da força de trabalho, realizando trabalho não } \\
\text { pago. Desta forma, a força de trabalho não paga é explorada } \\
\text { duplamente pelo capital e ainda possibilita a entrega de } \\
\text { mercadorias nos prazos estabelecidos. }\end{array}$ \\
\hline
\end{tabular}

Quadro 1: Categoria de Trabalhadores dos novos modos de ser da informalidade Fonte: Elaboração própria com base em Alves e Tavares (2009) 


\section{Trabalhonecessário}

Issn: $1808-799 X$

ano 14, número $24-2016$

Sob este mesmo aspecto, porém, considerando o termo nova informalidade, Krein e Proni (2010) também sinalizam expressões da informalidade no contexto de flexibilização das relações e regulações do trabalho. O Quadro 3 ilustra este processo.

\begin{tabular}{|c|c|}
\hline $\begin{array}{c}\text { Situação } \\
\text { Ocupacional }\end{array}$ & Descrição \\
\hline $\begin{array}{l}\text { PJ - Pessoa } \\
\text { Jurídica, quando } \\
\text { corresponde a uma } \\
\text { relação de emprego } \\
\text { disfarçada }\end{array}$ & $\begin{array}{l}\text { E uma pessoa que tem uma empresa, mas presta serviço de forma } \\
\text { regular e exclusiva a outrem. A relação de trabalho não é pautada pela } \\
\text { legislação trabalhista, mas constitui-se como um contrato comercial, em } \\
\text { que os contratados estão excluídos de todo o sistema de direitos e de } \\
\text { proteção social vinculado ao assalariamento. Na prática, isso pode } \\
\text { significar a legalização do que passou a ser chamado de "fraude de } \\
\text { pejotização", pois nessa modalidade de contratação os direitos } \\
\text { trabalhistas não existem. }\end{array}$ \\
\hline Falsas Cooperativas & $\begin{array}{l}\text { As cooperativas fraudulentas de mão-de-obra são uma das iniciativas } \\
\text { mais visíveis de utilização de novas formas de contratação que podem, } \\
\text { ser identificadas em grande parte dos casos, como uma relação de } \\
\text { emprego disfarçada. }\end{array}$ \\
\hline $\begin{array}{c}\text { Terceirização 1: } \\
\text { trabalho informal em } \\
\text { domicilio }\end{array}$ & $\begin{array}{l}\text { A informalidade não pode ser explicada pela terceirização mas a adoção } \\
\text { dessa técnica gerencial foi um mecanismo que contribuiu para sua } \\
\text { expansão de duas formas distintas: os incentivos a prestação de serviço } \\
\text { sem qualquer proteção previdenciária e trabalhista e o crescimento do } \\
\text { numero de pequenas empresas que prestam serviço para a indústria e } \\
\text { grandes empresas e que nem sempre cumprem a legislação trabalhista. }\end{array}$ \\
\hline $\begin{array}{l}\text { Terceirização 2: } \\
\text { relação de emprego } \\
\text { triangular }\end{array}$ & $\begin{array}{l}\text { (...) locação de mão-de-obra por meio de empresa de aluguel. o contrato } \\
\text { temporário é prestado por meio de uma empresa interposta que } \\
\text { seleciona e remunera trabalhadores com a finalidade de prestar serviços } \\
\text { provisórios junto as empresas clientes. Estabelece-se uma relação } \\
\text { triangular em que o local de trabalho não tem relação direta com o } \\
\text { empregador, mas com a agência de emprego. }\end{array}$ \\
\hline $\begin{array}{l}\text { Falsos Voluntários } \\
\text { do Terceiro Setor }\end{array}$ & $\begin{array}{l}\text { O problema é que nem sempre é nítido o caráter não lucrativo e a forma } \\
\text { como se dá a relação de trabalho, pois se admite que ela tenha algumas } \\
\text { características típicas de um emprego, tais como a pessoalidade, a } \\
\text { continuidade, e inclusive, a subordinação jurídica as determinações da } \\
\text { entidade pública ou privada, condição esta que deve ser estabelecida no } \\
\text { termo de adesão. }\end{array}$ \\
\hline Trabalho Estágio & $\begin{array}{l}\text { O trabalho estágio (não o estágio como complemento da formação } \\
\text { acadêmica) se caracteriza pela substituição de um profissional. Ou seja, } \\
\text { ele exerce uma atividade profissional como qualquer empregado. Assim, } \\
\text { constitui uma relação e emprego disfarçada, pois não é considerado um } \\
\text { emprego, nem tem a ele vinculado qualquer direito trabalhista ou } \\
\text { previdenciário. }\end{array}$ \\
\hline & Trata-se da utilização de trabalho autônomo como parte da estratégia de \\
\hline
\end{tabular}

TrabalhoNecessário - www.uff.br/trabalhonecessario; Ano 14, № 24/2016. 


\section{Trabalhonecessário}

Issn: $1808-799 X$

ano 14, número $24-2016$

\begin{tabular}{|c|l|}
\hline $\begin{array}{c}\text { Autônomo } \\
\text { Proletarizado }\end{array}$ & $\begin{array}{l}\text { empregadores, geralmente em uma relação triangular, para viabilizar } \\
\text { uma redução de custos e permitir rápidos ajustes ao ambiente das atuais } \\
\text { transformações econômicas e de reestruturação da produção de bens e } \\
\text { serviços, o que pode ser considerado uma relação de emprego } \\
\text { disfarçada. }\end{array}$ \\
\hline $\begin{array}{c}\text { Contratação por } \\
\text { prazo ou tempo } \\
\text { determinado }\end{array}$ & $\begin{array}{l}\text { As pessoas contratadas por prazo determinado têm dificuldade de } \\
\text { acesso às políticas de proteção social, especialmente o seguro } \\
\text { desemprego e a seguridade social (tempo de contribuição). }\end{array}$ \\
\hline
\end{tabular}

Quadro 3: Expressões da "nova informalidade" no Brasil

Fonte: Krein e Proni (2010).

As concepções abordadas sinalizam a precarização do trabalho como uma das principais expressões da Informalidade, entretanto, este entendimento tem diferentes conotações, visto que algumas das situações elencadas nos quadros atualmente são postas como alternativas viáveis para suprir o desemprego.

Para Lima (2007) a partir dos processos de flexibilização o trabalho informal adquire novo status em sua imprecisão conceitual, isto porque:

Velhos clusters de trabalho historicamente precários, voltados a mercados de baixa renda passam a ser vistos em sua positividade na geração de renda e produtos a custos competitivos. Tornam-se arranjos produtivos e, como tais, passam a compor propostas de políticas públicas. O trabalho ambulante, ilegal, em sweat shops, passou a ser tratado também como empreendedorismo, limitado não pela ausência do Estado, mas por sua presença excessiva. (p.136)

A partir desta reflexão verifica-se que a Informalidade não se configura apenas como uma alternativa ao desemprego, mas se institucionaliza a partir do momento que o Estado intervém por meio das Políticas Públicas. A maior evidencia desta questão fica clara no incentivo ao Empreendedorismo, propagado no Brasil como uma das principais estratégias para conter o desemprego e regulamentar as atividades informais.

Para Oliveira (2009) os benefícios do empreendedorismo como condição de empregabilidade e autonomia se revelam frágeis e contraditórios visto que as 


\section{Trabalhonecessário}

Issn: $1808-799 X$

ano 14, número $24-2016$

instituições que poderiam contribuir com os trabalhadores são as que mais impõem barreiras, expressas principalmente por meio da alta carga tributária e do excesso de burocracia.

Além disso, a concepção de empreendedorismo reduz o trabalhador ao aspecto econômico quando os processos de trabalho devem ser entendidos em suas múltiplas expressões e isto inclui o âmbito da saúde, segurança e dos direitos trabalhistas que devem ser assegurados aos trabalhadores. Pensar a garantia desses direitos e definir os riscos de acidente e impactos sobre a saúde desses trabalhadores requer considerar as particularidades das numerosas atividades desenvolvidas neste contexto.

De acordo com Mendes e Campos (2004) as atividades no trabalho informal geralmente acontecem em ambientes limitados e improvisados, onde é possível observar múltiplos fatores de risco para a saúde e também a ausência de mecanismos básicos de proteção.

Tais situações revelam a vulnerabilidade das condições de trabalho e entre os fatores mais agravantes se destaca a ausência de cobertura previdenciária, ou seja, em caso de acidentes ou doença os trabalhadores estão desprovidos de renda que os auxilie em suas necessidades, conforme sinaliza Lira (2012):

[...] os problemas associados à Informalidade vão além da maior precarização das condições de trabalho, implicam uma degradação da qualidade de vida e da proteção social, pois essas condições fazem com que os trabalhadores informais apresentem um grau de vulnerabilidade muito elevado, por não disporem de cobertura de Seguridade nem de qualquer direito trabalhista que possa ampará-los e às suas famílias em situação de afastamento temporário ou definitivo do trabalho (p.193).

As contribuições da autora apontam para a real condição de inúmeros trabalhadores que sobrevivem na Informalidade e estas características nada mais são do que as expressões do mundo do Trabalho Contemporâneo. E porque não dizer que estas algumas dessas situações podem também ser vivenciadas por 


\section{Trabalhonecessário}

Issn: $1808-799 X$

ano 14, número $24-2016$

aqueles que estão na relação de emprego formal, principalmente se considerarmos a flexibilidade dos contratos de trabalho. Fato é que todos estão sujeitos a Informalidade quando se vivencia um cenário duvidoso em que 0 formal vem sendo ameaçado cotidianamente.

\section{Considerações Finais}

Quando se questiona acerca dos possíveis (re)significados da Informalidade existe uma intenção clara em busca de respostas que novas configurações que este fenômeno assume no cenário contemporâneo. A partir das reflexões pontuadas pelos autores verifica-se que atualmente a Informalidade assume diferentes formas de ser e que acompanha a dinâmica do capital em todas as suas esferas.

A evidência preocupante está no fato de que suas expressões vêm ocultando o caráter de precarização que é inerente a estas atividades. A primeira constatação da precarização vem da condição de desemprego que leva os trabalhadores a buscarem a informalidade como alternativa de sobrevivência. Esta pode não ser uma regra para todas as situações, mas, os resultados das pesquisas científicas revelam que grande parte dos trabalhadores não optou por esta condição.

É fato também que muitos trabalhadores podem sinalizar diferentes opiniões, inclusive externando as vantagens da Informalidade, como por exemplo, ser o seu próprio patrão, ter seu próprio negócio, fazer o seu horário e outras expressões. Tal condição também faz parte deste contexto, visto que a exploração do trabalho em geral fica oculta nestas atividades, assume o caráter da autonomia.

Mas em geral, os trabalhadores informais vivenciam, em maior intensidade, as mudanças ocorridas no contexto do capital e sofrem os impactos das exigências impostas neste processo. Muitos já buscaram, em vão, retornar à 


\section{Trabalhonecessário}

Issn: $1808-799 X$

ano 14, número $24-2016$

condição de trabalhadores formais, porém, desistiram por não encontrar oportunidades em um mercado extremamente desigual.

Em linhas gerais, a partir das reflexões pontuadas neste artigo foi possível sugerir alguns pontos que caracterizam a precarização das atividades informais, são as seguintes:

- Instabilidade salarial;

- Flexibilidade das relações de trabalho;

- Desproteção social em termos previdenciários;

- Exposição aos riscos em decorrência da ausência de Equipamentos de proteção necessários à segurança;

- Impactos à saúde do trabalhador em diferentes níveis a depender da atividade;

- Ausência dos direitos trabalhistas;

- Desarticulação Sociopolítica dos trabalhadores;

- Omissão e falta de incentivos do Poder Público.

Frente a estas problemáticas verifica-se a necessidade em olhar para estas condições e propor a oferta de salários justos e a garantia de condições de trabalho que assegurem a integridade da saúde e segurança dos trabalhadores informais. Para tanto, sugere-se alguns caminhos que podem viabilizar tais questões, sendo os seguintes:

1. Execução de ações da politica pública de Emprego, Trabalho e Renda que, aliada a outras politicas públicas proporcione não apenas emprego, mas respostas às necessidades dos trabalhadores tais como saúde, educação, habitação e outros;

2. A articulação para o controle social uma vez que a formação dos Conselhos é formada por uma composição plural e paritária e privilegia o diálogo;

3. O fortalecimento das organizações sociopolíticas de trabalhadores informais tais como associações e sindicatos que priorizem como luta a autonomia no trabalho e acesso aos direitos sociais.

TrabalhoNecessário - www.uff.br/trabalhonecessario; Ano 14, № 24/2016. 


\section{Trabalhonecessário}

Issn: $1808-799 X$

ano 14, número $24-2016$

Considerando as questões expostas, o caminho parece desafiador, entretanto, trilhar os primeiros passos é necessário não apenas para a emancipação dos trabalhadores, mas para toda a sociedade que convive diariamente com o poder destrutivo do capital.

\section{REFERÊNCIAS}

ALVES, Maria Aparecida. TAVARES, Maria Augusta. A dupla face da informalidade do trabalho: autonomia e precarização. In: ANTUNES, Ricardo. Riqueza e miséria do trabalho no Brasil. São Paulo: Boitempo, 2006.

ANTUNES, Ricardo. Adeus ao Trabalho: ensaio sobre as metamorfoses e a centralidade do mundo do trabalho. 10ำ ed. São Paulo: Cortez, Campinas, SP: Editora da Universidade Estadual de Campinas, 2005.

. Os sentidos do Trabalho: ensaios sobre a afirmação e negação do trabalho. São Paulo: Boitempo, 2009.

CACCIAMALLI, M.C. Globalização e processo de informalidade. Economia e Sociedade, n.14, Unicamp. Campinas: 2000.

DEDECCA, Claudio Salvadori. Notas sobre a evolução do mercado de trabalho no Brasil. Revista de Economia Politica. vol.25, n. 1, p.94-111, janeiro-março, 2005.

KREIN, José Dari. PRONI, Marcelo Weishaupt. Economia informal: aspectos conceituais e teóricos. Escritório da Organização Internacional do Trabalho no Brasil. Brasília: OIT, 2010.

LIRA, Izabel Cristina Dias. Trabalho Informal como alternativa ao desemprego: desmistificando a informalidade. In: SILVA, Maria Ozanira Silva e. YAZBEK, Maria Carmelita. Políticas Públicas de Trabalho e Renda no Brasil Contemporâneo. 3o ed. São Paulo: Cortez, 2012.

MALAGUTI, Manoel Luiz. Critica à Razão Informal: a imaterialidade do salariado. São Paulo: Boitempo: Vitporia: EDUFES, 2000.

MARX, Karl. O Capital: crítica da economia política. 3. ed. São Paulo: Nova Cultural, 1988. 


\section{Trabalhonecessário}

Issn: $1808-799 X$

ano 14, número $24-2016$

MATTOSO, Jorge. O Brasil desempregado: como foram destruídos mais de 3 milhões de empregos nos anos 90. ㄴo ed. São Paulo: Editora Fundação Perseu Abramo, 1999.

MÉSZÁROS, István. Para além do capital: rumo a uma teoria da transição. Tradução: Paulo César Castanheira e Sérgio Lessa. Campinas: Editora da Unicamp, 2002.

OLIVEIRA, Marcio André. Trabalho Informal e Redes Sociais: os camelôs da Praça da Matriz em Manaus. 2009. 187f. Dissertação (Programa de Pósgraduação em Sociologia da Universidade Federal do Amazonas), 2009. Disponível em http://www.ppgsocio.ufam.edu.br/attachments/024> . Acesso em 20 julho de 2015.

PINTO, Geraldo Augusto. A origem do trabalho no século XX: Taylorismo, Fordismo, Toyotismo. 2ํe ed. São Paulo: Expressão Popular, 2010.

SILVA, Marcia Perales Mendes. Expressões do mundo do trabalho contemporâneo: um olhar para os trabalhadores do Parque Industrial de Manaus. Manaus: Editora da Universidade Federal do Amazonas, 2010.

SINGER, Paul. Trabalho Informal: Origens e Evolução. In: Jackbsen et all. Mapa do Trabalho Informal: perfil socioeconômico dos trabalhadores informais na cidade de São Paulo. São Paulo: Editora Fundação Perseu Abramo, 2000.

TAVARES, Maria Augusta. Acumulação, Trabalho e desigualdades sociais. In:. Serviço Social: Direitos Sociais e Competências Profissionais. Brasília: CFESS/ABEPSS, 2009.

THEODORO, Mario. As características do mercado de trabalho e as origens da informalidade no Brasil. In: RAMALHO, Jether Pereira. ARROCHELLAS, Maria Helena (org). Desenvolvimento, subsistência e trabalho informal no Brasil. São Paulo: Cortez; Petrópolis, RJ: Centro Alceu Amoroso Lima para a Liberdade, 2004

Recebido: 15 de junho de 2016

Aprovado: 22 de julho de 2016 